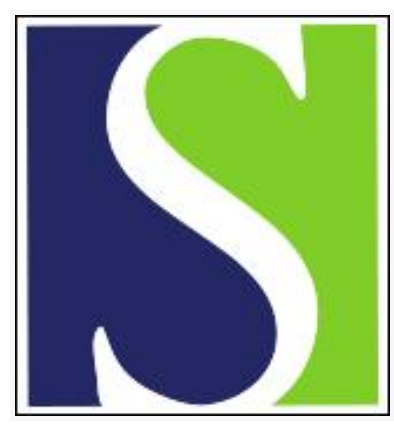

Scand J Work Environ Health 2002;28(3):141-157

https://doi.org/10.5271/sjweh.658

Issue date: Jun 2002

Health promotion trials at worksites and risk factors for cancer

by Janer G, Sala M, Kogevinas M

Affiliation: Respiratory and Environmental Health Research Unit, Insitut Municipal d'Investigació Mèdicina (IMIM), 80 Dr Aiguader Rd, 08003 Barcelona, Spain.

The following articles refer to this text: 2002;28(3):137-140;

2008;34(3):179-188

Key terms: alcohol; cancer; cancer prevention; diet; health behavior; health promotion; intervention trial; obesity; physical activity; review; risk factor; tobacco; worksite

This article in PubMed: www.ncbi.nlm.nih.gov/pubmed/12109553

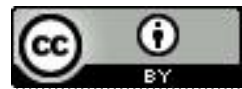




\title{
Health promotion trials at worksites and risk factors for cancer
}

\author{
by Gemma Janer, BSc, ${ }^{1}$ Maria Sala, MD, ${ }^{2}$ Manolis Kogevinas, $M{ }^{1}$
}

\begin{abstract}
Janer G, Sala M, Kogevinas M. Health promotion trials at worksites and risk factors for cancer. Scand J Work Environ Health 2001;28(3):141-157.

Studies of worksite health promotion have frequently reported larger effects than those at the community level. Many of these studies have serious methodological problems. Forty-five worksite health promotion trials following specific quality criteria were selected and estimated for behavioral changes in cancer risk factors and the effectiveness of different intervention components. Tobacco control programs found quit rates of about $5 \%$ with relapse rates of $40 \%$ to $80 \%$ at 6 months after the intervention. Effectiveness increased with the duration of the intervention for at least 6 months, repeated contacts with the participants, continuous support, and tailored messages. There was less evidence for the long-term effectiveness of incentives. Trials on diet, alcohol, physical activity, overweight, and solar radiation showed the same positive trends. The overall evidence indicates a modest but positive effect of health promotion trials at worksites and the effect, for smoking cessation trials, is slightly larger than that of community-based trials. Many of the recommendations made to increase participation and effectiveness were not based on empirical data.
\end{abstract}

Key terms alcohol, cancer prevention, diet, health behavior, intervention trials, obesity, physical activity, review, tobacco.

Health promotion programs encourage people to adopt healthy life-style behavior on the assumption that it will result in improved health. Big community-based health promotion trials have, however, reported only modest effects [eg, COMMIT and other trials $(1,2)]$. In recent years, numerous health promotion studies have been conducted at the worksite level. Risk behavior has been addressed in health promotion trials concerning tobacco cessation, diet changes such as increases in fruit and vegetable consumption, control of cholesterol levels, physical activity and loss of weight, exposure to ultraviolet light, stress, alcohol and drug abuse, and other such issues.

These studies, and reviews of these studies, have frequently reported more significant changes than those of community-based trials, such as tobacco quit rates of the order of $10-15 \%(3,4)$. It has frequently been assumed that worksite health promotion must have a positive ef- fect, and many of these studies were not adequately designed to evaluate whether such an effect was present. Many studies did not have a reference group, they were based on a small number of subjects, and they did not give quantitative estimates of the changes achieved by the interventions. Properly controlled large intervention trials at worksites tend to report a positive, but only modest effect (4-7).

In this review we focus on worksite health promotion trials on major cancer risk factors, including tobacco, diet, physical activity, obesity, ultraviolet light, and alcohol consumption. In contrast to other existing reviews, we selected studies on the basis of specific quality criteria and have reported quantitative estimates of the changes achieved and have drawn conclusions on the basis of the quantitative estimates. The application of meta-analytic techniques was possible only to a limited extent due to the heterogeneous design of the

1 Respiratory and Environmental Health Research Unit, Institut Municipal d'Investigació Mèdica (IMIM), Barcelona, Spain.

2 Department of Health, Municipality of Sabadell, Sabadell, Spain.

Reprint requests to: Dr Manolis Kogevinas, Respiratory and Environmental Health Research Unit, Institut Municipal d'Investigació Mèdica (IMIM), 80 Dr Aiguader Rd, 08003 Barcelona, Spain. [E-mail: Kogevinas@imim.es] 
trials. This review was prepared within the framework of the European project PREWORK (prevention of risk factors for cancer at the worksite).

\section{Subjects and methods}

\section{Search methodology}

Bibliographic searches were done through the online database Medline, searches in our own archives, backward searches of articles cited in earlier literature reviews, and backward searches of reports on health promotion trials at worksites. The keywords used in the Medline search were "employee OR worksite OR workplace OR occupational health services" AND "wellness program OR health promotion OR health education OR health behavior" in combination with keywords for specific risk factors such as: "tobacco control OR tobacco", "diet OR nutrition", etc. We initially identified more than 1000 papers and reviewed approximately 200 articles with some reference on health promotion programs at worksites.

Table 1. Description of the principal features of the worksite health promotion trials $(\mathrm{N}=45)$.

\begin{tabular}{|c|c|c|}
\hline & \multicolumn{2}{|c|}{ Trials } \\
\hline & $\mathrm{N}$ & $\%$ \\
\hline \multicolumn{3}{|l|}{ Risk factors } \\
\hline One risk factor & 30 & 67 \\
\hline Multiple risk factors & 15 & 33 \\
\hline Tobacco & 27 & 60 \\
\hline Diet & 16 & 36 \\
\hline Physical activity & 14 & 31 \\
\hline Weight control & 8 & 18 \\
\hline Alcohol & 3 & 7 \\
\hline Solar radiation & 1 & 2 \\
\hline \multicolumn{3}{|l|}{ Country } \\
\hline United States & 29 & 64 \\
\hline European countries & 7 & 16 \\
\hline Australia & 5 & 11 \\
\hline Other & 4 & 9 \\
\hline \multicolumn{3}{|l|}{ Intervention characteristics } \\
\hline Environmental in nature & 17 & 38 \\
\hline Incentives included & 12 & 27 \\
\hline Intervention tailored & 18 & 40 \\
\hline $\begin{array}{l}\text { Workers involved in planning and } \\
\text { implementing the program }\end{array}$ & 12 & 27 \\
\hline Short duration ( $\leq 3$ months) & 26 & 58 \\
\hline Long duration (>3 months) & 19 & 42 \\
\hline \multicolumn{3}{|l|}{ Worksite size } \\
\hline Large (>500 workers) & 22 & 49 \\
\hline Medium (100-1500) & 22 & 49 \\
\hline Small $(<100)$ & 1 & 2 \\
\hline Total & 45 & 100 \\
\hline
\end{tabular}

\section{Selection criteria}

For this review, we selected 45 trials on the basis of the following criteria: (i) trials referring to tobacco control, diet control, physical activity, obesity, ultraviolet light, and alcohol consumption; (ii) health promotion trials at worksites with a control no-intervention group or with an evaluation of different types of interventions in the same study; (iii) studies examining outcomes directly related to health (ie, studies evaluating only absenteeism or work productivity were excluded); (iv) studies including more than 100 subjects and a minimum of 50 subjects in each study group; (v) articles in English, French, or Spanish; (vi) studies in peer-reviewed journals. A high participation rate was also included a priori in the inclusion criteria but was dropped due to the difficulties in calculating the comparable rates of the trials.

\section{Characteristics of the trials}

We reviewed a total of 45 health promotion studies (table 1). Most ( $\mathrm{N}=27)$ of them focused on tobacco control either exclusively (8-21) or as part of a wider health promotion program (22-34). Sixteen health promotion programs focused exclusively (35-43) or in part (23$27,31,34,43)$ on diet. An increase in physical activity was the goal for 14 health promotion trials; in 3 it was the exclusive factor (44-46), and in 11 it was part of a wider health promotion program $(24,25,29-34,43,47$, 48). Finally, fewer studies focused on other risk factors $(22,28,29,32,34,38,43,45,49-52)$ (table 2).

\section{Target population}

Most trials reported interventions in the United States $(\mathrm{N}=29,64 \%)$ (table 1). The criteria used to select workplaces for the trials were clearly stated in $12(12,13$, $17,22,26,28,29,31,35,36,38,51)$ of the 45 trials. The criteria used included number of workers $(13,22$, $26,29,36)$, low turnover rates $(31,36)$, high response rate at baseline (22), or acceptability of the program before the randomization process (11). The individual inclusion criteria also varied among the studies in that most of the studies included all or a sample of workers in a worksite, two trials included only at-risk populations $(32,42)$, and six trials used only volunteers (15$18,32,44)$. The companies selected were mostly services and manufacturing plants. The proportion of bluecollar workers varied among the studies but, overall, half of the workers covered by health promotion programs were blue-collar. Although programs were addressed to workers independently of gender, out of the 45 trials 
Table 2. Design characteristics of the worksite health promotion trials and the types of intervention used.

Trial Number of worksites and participants Type of intervention

Trials focusing on smoking

Glasgow et al (26); United States, 1984 Intervention A: 361 workers

Intervention B: 215 workers

Jason et al (11); United States, 1987

Windsor et al (15); United States, 1988

Intervention A: 95 workers Intervention B: 94 workers Intervention C: 95 workers Intervention D: 94 workers

Omenn et al (9); United States, 1988

Six intervention groups $(A-F)$ : 402 workers
Intervention A: pulmonary function tests, warning not to continue smoking, pamphlet detailing plan for quitting Intervention $B$ : same as $A$ and 3 to 5 minutes of counseling to secure commitment to behavioral plan outlined in the pamphlet

Intervention A: 21 worksites, 233 workers Intervention A: six 45-minute support group meetings twice a Intervention B: 22 worksites, 192 workers week; use of a manual's activities and televised news program Intervention B: a manual's activities and televised program

Intervention A: self-help manual Intervention $\mathrm{B}$ : same as $\mathrm{A}$ and skill training plus enhancement of social support

Intervention $\mathrm{C}$ : same as $\mathrm{A}$ and monetary incentives Intervention D: same as B and monetary incentives

Interventions A and D: multiple component program: behavioral skills training, aversive stimuli, imagery, and stress management ( 3 weeks, intensive quit period) Interventions B and E: prevention of relapse (8 weeks) Interventions $C$ and $F$ : self-help pamphlet Interventions $A$ and $B$ in group-help format Interventions $D$ and $E$ in self-help format

Jason et al (10); United States, 1989

Intervention A: 19 worksites, 206 workers Intervention A: six 45-minute support group meetings, 2 a Intervention B: 19 worksites, 213 workers week during a 3-week television program; focused on reviewing techniques discussed in the television program and self-help manuals; followed by 12 1-hour monthly meetings Intervention B: same as A and financial incentives

Hymowitz et al (16); United States, 1991 Intervention A: 3 worksites, 131 workers Intervention B: 3 worksites, 121 workers

Intervention A: volunteers participated in a 5-week training program for quit-smoking group leaders and received additional training and support

Intervention B: volunteers participated in the training program but did not carry out protocols for health education and smoking policies

Volunteers in both interventions led 8 successive 2-hour weekly sessions and brief maintenance or follow-up sessions

Glasgow et al (13); United States, 1993 Intervention: 9 worksites, 474 workers Control: 10 worksites, 623 workers

Incentive program: smokers encouraged to support each other; stop smoking counseling, materials, or advice; incentives to encourage support from nonsmokers

During 3 months: 3 1-hour smoking cessation classes, 1-hour class to promote co-worker support of smoking cessation; 90 minute consultation with company representatives on ways to implement nonsmoking policies

Intervention A: same as control and incentives Intervention B: same as A and group meetings during initial 3week phase, 14 booster meetings next 6 months Control: media intervention, self-help manual, newspaper supplement

Intervention A: 4 worksites, 274 workers Intervention B: 4 worksites, 234 workers

Willemsen et al (17); The Netherlands 1998

Koffman et al (20); United States, 1998

Intervention A: 1 worksite 81 workers Intervention B: 1 worksite 68 workers

Razavi et al (21); Switzerland, 1999

Intervention A: 135 workers Intervention B: 88 workers Control: 121 workers
Intervention A: self-help manuals, smoking cessation group course, educational exhibition at strategic locations in the work sites, smoking restriction in some areas; repeated after 1 year Intervention B: self-help manuals

Intervention A: self-help package, support teams, monthly telephone counseling, maintenance sessions Intervention B: same as A plus a cash-incentive competition contest

Intervention A: group discussion led by professional (90 minutes per session), role playing, information and education about relapse, peer pressure Intervention B: group discussion led by former smokers 
Table 2. Continued.

\begin{tabular}{lll}
\hline Trial & Number of worksites and participants & Type of intervention \\
\hline Lang et al (8); France, 2000 & Intervention A: 13 physicians and & Intervention A: 5 to 10 minutes of information \\
& $\begin{array}{l}1773 \text { workers } \\
\text { Intervention B: } 15 \text { physicians and }\end{array}$ & $\begin{array}{l}\text { Intervention B: contract proposed by physicians to smoker during } \\
\text { annual examination, fixed date for smoking cessation, phone call, } \\
\text { second visit }\end{array}$
\end{tabular}

Kadowaki et al (19); Japan, $2000 \quad$ Intervention: 132 workers Delayed intervention:131 workers

\section{Trials focusing on diet}

Hebert et al (36), Sorensen et al (53), Hunt et al (54), Hebert et al (55); United States, 1993

Barratt et al (42); Australia, 1994

Reynolds et al (41); United States, 1997 Intervention A: 236 workers Intervention: 5 worksites Control: 8 worksites 1762 workers in analysis Intervention A: 310 workers Intervention B: 114 workers Control: 259 workers Intervention B: 284 workers Delayed intervention: 115 workers

Tilley et al (35); United States, 1999

Intervention: 15 worksites Control: 13 worksites, 5042 workers

Sorensen et al (37), Hunt et al (56); United States, 1999

Intervention A: 7 worksites Intervention B: 7 worksites Intervention C: 8 worksites 1088 workers

Braeckman et al (38); Belgium, 1999

Buller et al (39); United States, 1999

Sasaki et al (40); Japan, 2000

\section{Trials focusing on physical activity}

Shephard (45), Leatt et al (57),

Cox et al (58); Canada, 1992

Heirich et al (44); United States, 1993
Intervention: 2 worksites, 272 workers Control: 2 worksites, 366 workers

Intervention A: 41 groups, 332 workers Intervention B: 41 groups, 363 workers

Intervention: 94 workers Control: 192 workers

Intervention: 1200 workers Control: 800 workers

Intervention A: 493 workers Intervention B: 503 workers Intervention C: 481 workers Intervention D: 403 workers
Face-to-face counseling; personal decision and declaration on when to start smoking cessation; explanation on how to deal with difficult situations; periodic visits, leaflet distribution and group discussions for encouragement

Eight discrete food-based eating pattern messages; programs targeting employee eating behavior and changes in worksite environment

Intervention A: self-help package

Intervention B: nutrition course: five 1-hour sessions led by a dietician

Intervention A: information on serum cholesterol value, self-help booklet on adopting a healthier diet

Intervention B: self-help booklet

Delayed intervention: self-help booklet after completing the study

Five nutrition classes, mailed self-help materials; worksite posters after personalized feedback after 12-months

Intervention $\mathrm{A}$ : same as $\mathrm{C}$ and worker participation in program planning and implementation, programs aimed at individual behavior change, and changes in worksite environment Intervention B: same as A including worker's family Intervention C: periodic exposure to national 5-a-day media campaigns, promotion of cancer information service hot line, 1hour general nutrition presentation and taste test

Intervention: 3-month education program after baseline screening; mass media, posters, leaflets, video, 2-hour educational session, newsletter

Control: screening and summary of results

Intervention A: baseline awareness of 5-a-day program (increase in vegetable and fruit consumption)

Intervention B: peer education program by an employee in each intervention group; this employee received 16 hours of training over an 8-week period and was expected to spend 2 hours per week discussing eating fruits and vegetables with co-workers; use of printed five-a-day material

Education plan based on the individual results of pre-intervention dietary assessment, 15 minutes of individual counseling by nurses; weekly newsletter

Fitness-centered life-style program; members offered use of gymnasium and participation in two to three $30-$ to- 45 minute supervised exercise sessions per week

Intervention A: health education, and special events to encourage awareness of health issues

Intervention B: fitness facility with physical fitness equipment and trainers

Intervention C: direct outreach and personal counseling with employees at cardiovascular risk

Intervention D: same as C but targeting all employees, combined with organized physical fitness activities and some exercise equipment 
Table 2. Continued.

\begin{tabular}{|c|c|c|}
\hline Trial & Number of worksites and participants & Type of intervention \\
\hline Marcus et al (48); United States, 1998 & $\begin{array}{l}\text { Interventions } A \text { and } B, 11 \text { worksites, } \\
1559 \text { workers }\end{array}$ & $\begin{array}{l}\text { Intervention A: employees received a personalized letter and } 1 \\
\text { of } 5 \text { self-help manuals focusing on } 1 \text { of the } 5 \text { stages of } \\
\text { motivational readiness for change; } 1 \text { month later they received } \\
\text { the following one } \\
\text { Intervention B: five manuals currently available on physical activity }\end{array}$ \\
\hline Emmons et al (47); United States, 1999 & $\begin{array}{l}\text { Intervention: } 13 \text { worksites } \\
\text { Control: } 13 \text { worksites, } \\
2055 \text { workers }\end{array}$ & $\begin{array}{l}\text { Environmental changes: space, showers, equipment, discounts } \\
\text { on memberships; discussions of ways to support a more } \\
\text { physically active workforce }\end{array}$ \\
\hline $\begin{array}{l}\text { Peterson \& Aldana (46); United States, } \\
1999\end{array}$ & $\begin{array}{l}\text { Intervention A: } 174 \text { workers } \\
\text { Intervention B: } 168 \text { workers } \\
\text { Control: } 185 \text { workers }\end{array}$ & $\begin{array}{l}\text { Intervention A: stage-based intervention group: written messages } \\
\text { tailored to individual stage of change } \\
\text { Intervention B: generic intervention group: nontailored materials }\end{array}$ \\
\hline Kishchuk et al (50); Canada, 1994 & $\begin{array}{l}\text { Intervention: } 451 \text { workers } \\
\text { Placebo: } 74 \text { workers } \\
\text { Control: } 289 \text { workers }\end{array}$ & $\begin{array}{l}\text { Intervention: alcohol group program } \\
\text { Placebo: nutrition group program } \\
\text { Both sessions delivered by a trained health professional }\end{array}$ \\
\hline
\end{tabular}

Wodak (51); Australia, 2000

Intervention: 33 worksites, 631 workers Control: 34 worksites, 575 workers

Trials focusing on weight control

Anderson et al (49); United States, 1993 Intervention A: 4 worksites, 58 workers

Intervention B: 10 worksites, 57 workers

Trials focusing on occupational exposure to solar radiation

Girgis et al (52); Australia, $1994 \quad$ Intervention: 127 workers

Trials focusing on weight control (diet, physical activity)

Shannon et al (43); United States, 1987 Intervention: 52 workers Delayed intervention: 51 workers

Trials focusing on weight control, diet, physical activity, smoking \& alcohol Kronenfeld et al (34); United States, 1987 Intervention: 18 worksites, 142 workers Delayed intervention: 313 workers (number of worksites not reported)

Trials focusing on diet, weight control, smoking \& other risk factors

Breslow et al (25), Sorensen et al (59); Intervention A: 4 worksites, 2600 workers Intervention A: 1-hour, nurse-administered health profile on United States, 1990 Intervention B: 3 worksites, 1700 workers

Lunchtime seminars, films, opportunity to take health risk appraisal; encouraging agency policy changes; quarterly newsletters, special events to encourage walking

Skin screening and education sessions: specific information on means of modifying health risk behavior, information on personal vulnerability

Introductory session on nutrition to general health, 8 sessions dealing with weight control, in a 9-week program; monitoring follow-up planned, but impossible to conduct

behavioral, attitudinal and biometric measures; 3-hour life-style seminar to introduce the program, and various behaviorally oriented programs

Intervention B: same as A and 3-phase, professionally delivered, behaviorally oriented cessation program

Trials focusing on physical activity \& smoking

Erfurt et al (28); United States, $1991 \quad$ Intervention A: 1374 workers Intervention B: 2089 workers Intervention C: 1893 workers Control: 2448 workers

Trials focusing on smoking \& weight control

Jeffery et al (22); United States, 1993 Intervention: 16 worksites, 270 workers in smoking program, 2041 workers in weight program Control: 16 worksites

Intervention A: health risk appraisal, media promotion, health improvement classes

Intervention B: same as A and support, encouragement and assistance in problem solving, broad range of types of services or interventions

Intervention C: same as B and plant organization activities Control: initial screening and re-screening

On-site classes economic incentives; 4 rounds of 11 biweekly sessions 
Table 2. Continued.

\begin{tabular}{|c|c|c|}
\hline Trial & Number of worksites and participants & Type of intervention \\
\hline Glasgow et al (26); United States, 1995 & $\begin{array}{l}\text { Intervention: } 13 \text { worksites } \\
\text { Delayed intervention: } 13 \text { worksites } \\
1222 \text { workers }\end{array}$ & $\begin{array}{l}\text { Four activity classes (motivational-incentive, educational-skills } \\
\text { training, policy-environmental, and maintenance) }\end{array}$ \\
\hline $\begin{array}{l}\text { Sorensen et al (23); United States, } 1996 \\
\text { Blair et al (60); United States, } 1986\end{array}$ & $\begin{array}{l}\text { Intervention: } 54 \text { worksites } \\
\text { Control: } 52 \text { worksites } \\
28000 \text { workers }\end{array}$ & $\begin{array}{l}\text { Kick-off event, interactive activities, posters and brochures, self- } \\
\text { assessments, self-help materials, campaigns and contests, direct } \\
\text { education through classes and groups, and environmental change }\end{array}$ \\
\hline
\end{tabular}

Trials focusing on smoking, diet \& physical activity

Glasgow et al (27); United States, 1997 Intervention: 11 worksites Delayed intervention: 11 worksites 1066 workers

Four activity classes (motivational-incentive, educational-skills training, policy-environmental, and maintenance)

Trials focusing on smoking, alcohol, diet, physical activity \& other risk factors

Maes et al (24); The Netherlands, 1998 Intervention: 1 worksite Control: 2 worksites

346 workers

changes; incentives

Trials focusing on cardiovascular risk reduction (smoking, physical activity)

Kornitzer et al (30); Belgium, $1983 \quad$ Control: 15 worksites

Intervention: 15 worksites

19409 workers

Trials focusing on cardiovascular risk reduction (smoking, physical activity, diet)
Bauer et al (31), Rose et al (61);

United Kingdom, 1985

Control: 5 worksites

Intervention: 5 worksites

8743 workers

Trials focusing on cardiovascular risk reduction (smoking, physical activity)

Spilman et al (33); United States, 1986 Intervention: 642 workers

Control: 556 workers
Half-hour intervention sessions 3 times per week on physical exercise and life-style; groups oriented around smoking, headaches, or back pain; training in social skills and leadership for management; organizational and environmental

Preventive counseling for high-risk subjects, 3 times in first year, 2 times in second year, and yearly thereafter; yearly individual counseling for a $5 \%$ random sample and a nonrandom $5 \%$ of the lower-risk group; in factories with canteens advice to the cook on reduction of total calories, saturated fats, and cholesterol

General education campaign over 5-to-6-year period: pamphlets, lectures, cooking demonstrations (for wives), posters, and films; personal letter to smokers wanting to quit suggesting methods to stop smoking; personalized advice by a physician for high-risk workers, 2 further screening examinations with feedback; evening meetings for men and their wives

Designed to create a work environment supportive of positive health practices; risk assessment efforts and health education modules; offered 3 times; the fitness module met 3 times a week for 12 weeks; the low-back module met twice a week for 6 weeks; other modules varied in length from 4 to 12 weeks and met once a week for 1 to 1.5 hours each session

Trials focusing on cardiovascular risk reduction (smoking, physical activity, weight control)

Edye et al (32); Australia, $1989 \quad$ Intervention A: 1076 workers Intervention B: 861 workers

Intervention A: individual information on risk factors by a physician

Intervention B: information of risk factors initial counseling by a physician, opportunity to attend three counseling sessions by nurses over a 3-month period

Trials focusing on cardiovascular risk reduction (smoking, physical activity)

Gomel et al (29); Australia, 1993

Intervention A: 10 worksites, 130 workers Intervention B: 8 worksites, 82 workers Intervention C: 6 worksites, 124 workers Intervention D: 4 worksites, 95 workers
Intervention A: major risk factors assessed feedback provided to each participant (30 minutes)

Intervention B: same as A and standardized advice on life-style changes required to reduce heart disease risk factors (50 minutes)

Intervention C: same as B and 6 life-style counseling sessions in a 10-week period; self-instructional life-style change manual, on a 4-stage model of behavior change (around 3 hours) Intervention D: same as B and life-style change manual, goalsetting and follow-up counseling session, incentives (2.5 hours) 
reviewed, 15 included more than $70 \%$ men $(8,9,14$, $17,19,28-31,35,38-40,50,51)$ and 3 had more than $70 \%$ women $(37,42,49)$.

\section{Selection of intervention and control groups}

In 24 intervention trials, the control groups did not receive any kind of intervention except baseline assessments $(10,12,13,19,21,22,24,26-28,31,33-36$, $40-43,45,46,50-52)$. In 16 trials, the control groups received minimal intervention, such as self-help materials, warning, or counseling $(8,9,14,15,17,18,23,29$, $30,32,34,37-39,46,47)$. Finally, four trials only compared the effect of different kinds of intervention (16, 20, 44, 49). Assignment to a control or intervention group was randomized in 32 trials and not randomized in the remaining ones. Cluster randomization was frequently applied to avoid contamination among workers assigned to the intervention and control groups and also to handle ethical concerns. The unit of randomization was the workplace in 18 trials $(11-13,16,18,22,24$, $26-31,35-37,44,47)$, the workplace physician in 1 trial (8), depots (38) in 1 trial, and networks in 2 trials (39, 51). Nine studies did individual randomization of workers of the same industry or department $(9,14,15,19$, $32,33,41,46,50)$. A cross-over design was applied in six studies $(19,26,27,34,41,43)$, which offered delayed intervention to the control group.

\section{Analysis}

A characteristic feature of cluster randomization studies is that the natural variability in response among clusters exceeds the variability in response within clusters (62). Eight studies $(11,18,23,26,27,31,39,48)$ matched subjects or clusters to factors such as worksite size, gender distribution, blue- and white-collar distribution, and other factors. Four studies stratified worksites in the design phase before the randomization (11, $13,36,37)$. Most of the trials used worksite, or whatever unit of cluster randomization, as the unit of analysis $(8,11,13,22,26,27,39)$. Those using workers as the unit of analysis took into account the effect of the cluster randomization procedure by incorporating a nested design structure $(29,36,37,51)$ or by using other procedures $(18,30,31,35,47)$. Seven trials did not take cluster randomization into account when analyzing their data $(12,16,24,28,38,47,49)$.

\section{Intervention characteristics}

The interventions included in the health promotion programs reviewed are described in table 2. Methods for recruitment and the intensity of the recruitment process differed among the studies and included, for example, annual medical examination $(8,14)$, letters or phone calls $(12,13,15,17,22,38,39)$, and recruitment through group leaders or union representatives $(11,29$, $50)$.

Interventions can be classified according to delivering modalities. They can be directed towards individuals, groups, or all the workforce through environmental changes (eg, changes in products of vending machines). They can be offered by the workplace physician $(8,14$, $16,31,50)$, by other workers $(20,24,26,27,33,39$, 43-45), or by external experts $(9,11,15,17-19,22,28$, $30,32,34,38,42,45,48,50,52)$. Apart from face-toface contact, the interventions used letters, videos, posters, and phone calls.

The process (contents) of the interventions can be classified into those aiming at improving workers' knowledge and awareness of certain risk factors, helping workers to make behavioral changes, and creating environments facilitating healthy life-styles. The first strategy offers information, such as an explanation of the quit process or of the relation between physical activity and health. The second strategy offers persuasion and techniques to develop skills, such as learning to avoid tempting situations or identifying personal barriers to the adherence to healthy behaviors. Environmental or structural interventions start changing the environment without requiring individual participation in educational activities, such as banning smoking in certain areas or changing available food in the canteen. Most programs included both awareness and behavioral change factors. Occasionally, environmental and structural interventions were added.

Most health promotion programs offered an initial medical screening, questionnaires, or interviews to obtain worker health profiles. Thereafter, the treatment group received some kind of intervention. Occasionally intervention messages were adapted to the results obtained in this baseline assessment (tailored interventions, see table 1), following in some studies the stages-ofchange theory $(20,26,27,29,35,46)$. For example, in a smoking cessation trial, workers would be classified as at the precontemplation stage if they did not intend to quit smoking in the next 6 months, as at the contemplation stage if they intended to quit smoking within the next 6 months, and at the preparatory stage if they wanted to quit smoking in the next month or if they had seriously attempted to quit smoking during the last year. Workers would then receive different types of intervention depending on the stage. For example, workers in an "early" stage would be asked to consider the health risks of being overweight, having high cholesterol, or smoking, while those in a "later" stage would be asked to change their diet or tobacco use or to maintain a healthy life-style. 
To achieve better results with behavioral changes, some interventions included support over time $(15,17$, $19-21,28,31,32,34,40,50)$, involvement of family members (37), within and between company competitions or incentives $(10,13,18,20,22,26,27,29,37$, 47 ), or participation of the occupational health services of the company in program planning and implementation $(15-17,20,23,24,26-28,31,34,39)$.

\section{Outcomes}

The outcomes measured in the trials were participation rates in health promotion activities, knowledge improvement on risk factors, alterations of states of change, behavioral changes, changes in biological parameters, and morbidity and mortality incidence reduction.

\section{Results}

\section{Participation}

Almost all the trials provided some information on participation rates (figure 1), but only a few reported comprehensive data for different stages of the study $(10,12$, $22,28,50)$. Worksite or physician participation rates were reported in 11 trials, and they ranged from $17 \%$ (8) to $100 \%$ (19). Reasons for no participation were lack of interest in health promotion programs, strikes, or participation in other health promotion programs. Response rates for individuals were reported in most trials for baseline and follow-up assessments. The response rates

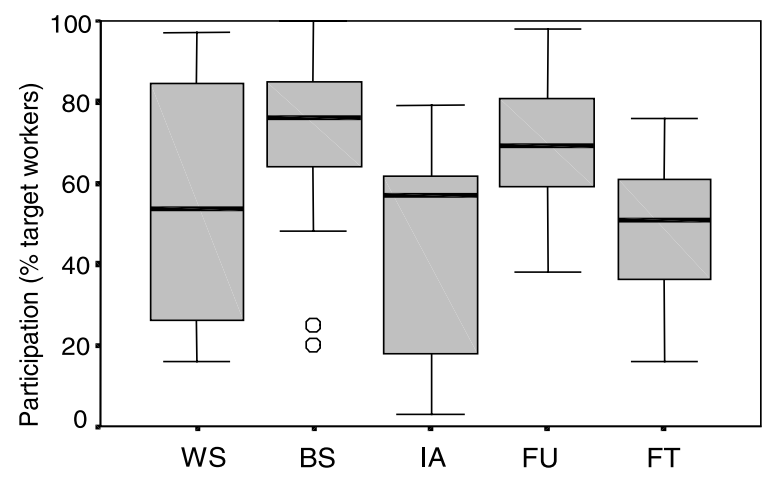

Figure 1. Participation rates at different stages of worksite health promotion (median, 25th and 75th quartile, range, and outliers). [WS = worksite, $\mathrm{BS}=$ baseline survey, $\mathrm{IA}=$ intervention activities, $\mathrm{FU}=$ follow-up (ie, participation at follow-up among baseline respondents), $\mathrm{FT}=$ follow-up in the total target population (ie, participation at baseline $x$ follow-up). For nine trials that did not report the follow-up of the total target population, it was calculated by us. of selected workers in the baseline assessment ranged from $20 \%$ (15) to $90 \%$ (43) with an average of $71 \%$, while those at follow-up ranged from $43 \%$ (27) to $98 \%$ (11) of the subjects who completed the baseline assessments, the average being $69 \%$. Finally, participation in the health promotion activities was reported in seven trials, and it ranged from $12 \%$ (12) to $83 \%$ (32). The median participation of the target population at follow-up (including also those not participating in the baseline survey) was $49 \%$ (figure 1).

There are limited data on whether (and which) baseline characteristics of the target population are associated with participation rates. Factors that have led to higher response rates in the baseline or follow-up surveys in some studies have been gender (male), higher educational attainment, white-collar worker, older age, marriage, white non-Hispanic worker, and other factors related to specific risk factors, such as lower smoking prevalence (24). Factors influencing participation in program activities have been smaller worksites (12), gender (female), professional and clerical or sales job in a tobacco control program (22), and younger, better educated person, and active employment in a nutrition program (35).

The strategies used to recruit a high number of participants and to maintain low attrition rates differed between the studies. The involvement of workers in the planning and implementation of the intervention was the most common policy used to increase participation. Participation rates in the intervention activities with workers' participation $(16,17,23,26-28,31,33,39)$ were, however, the same if not lower than those without it. A direct comparison of participation rates was, however, complicated since the studies differed in many aspects apart from worker participation. Only one trial offered the same intervention first without and then with the involvement of workers in the planning and implementation and increased the participation rate from $15 \%$ to $65 \%$ (24).

Some health promotion programs offered economic incentives or within or between worksite competitions intending to improve both participation rate and behavioral change. It was difficult to evaluate the influence of incentives on participation by comparing studies with or without incentives because there were many other differences between the studies and only a few of them reported data on participation. One trial offered the same intervention, however, with and without incentives and did not find any improvement in the participation rates (29).

The statistical treatment of nonresponse varied among the studies. In the analysis, one trial included the companies that did not agree to participate after having been assigned to the treatment group (36), while all the other trials excluded these companies from the analysis. Workers who were assigned to the intervention group but did not participate in the health promotion 
activities were usually included in the analysis, while those who did not complete the baseline assessments could not be included in the analysis. Occasionally, in smoking control trials, those lost to follow-up were included in the analysis and were treated as if they were still smokers $(8,13,15,17,19,42)$.

\section{Smoking cessation programs}

A higher quit rate was observed in the group receiving the intervention in all 16 of the smoking cessation programs that reported this outcome $(8-15,17-19,25-$ 29). The magnitude of the effect of the intervention varied considerably between the studies (figure 2 ) and was statistically significant in $9(9-12,14,15,18,19,28)$ of the 13 studies reporting statistical significance $(8,26$, $27,29)$. The average smoking cessation rate was $6.1 \%$, ranging from $0.9 \%$ to $12 \%$, when quit rates in the intervention groups were compared with those of the control groups (figure 2). For the 13 studies providing complete information allowing the calculation of means and standard errors $(8-10,12-15,18,19,26-29)$, this average was $5.3 \%$. The weighted mean of the quit rates (weighted by the inverse of the standard error) was very similar (5.4\%). For the calculation of this weighted sample, the size of some studies had to be estimated because exact data were not provided.

The quit rates of the intervention groups were of the order of $10-15 \%$, if the changes observed in the control group were not taken into account. In some of these studies $(\mathrm{N}=6)$, the control groups were not re-contacted after the baseline surveys examining the prevalence of risk factors in the study population $(10,12,19,26-28)$, while in others $(\mathrm{N}=8)$ the control groups received a variable amount of information on tobacco control $(8,9$, $13-15,18,25,29)$. On most occasions this information was limited to minimal informative material distributed at the beginning of the intervention. The results varied considerably between these studies. Overall, however, the quit rates were similar in the studies using control groups without intervention (6\%) as compared with those using control groups with minimal intervention $(6 \%)$.

Changes in smoking prevalence at the end of the intervention were sometimes reported $(8,22,27,31-34)$. These changes accounted for quit and relapse rates and ranged from $0.5 \%$ to $6 \%$. Quit rates could not be calculated, therefore, for these studies. Similarly, changes in smoking prevalence could not be calculated for the remaining studies since they did not provide relapse rates for the whole study population. Continuous abstinence rates were reported in six trials, and they ranged from $1 \%$ to $6 \%(8,14,16,17,21,23)$. An increase in the number of attempts to quit smoking (17\% and $13 \%$ ) was found in both studies that examined this outcome (12,
27). Progression through stages of change was evaluated in one study, which found a progressive tendency towards higher stages of the quitting process (27). A reduction in the number of cigarettes smoked per day ( 2.5 and 3.6 cigarettes/day) was found in two $(11,31)$ out of four studies evaluating this outcome $(10,14)$. Another trial reported a $20 \%$ reduction in heavy smokers (more than 30 cigarettes/day) (34).

The effect of the interventions on smoking behavior over time was evaluated in 11 studies $(9-12,13,15,17-$ $19,21,29)$. In nearly all of them, the effects observed after the intervention attenuated over time (figure 3 ). At about 6 months after the end of the intervention, the effect of the intervention was reduced by approximately $40 \%$ to $80 \%$. It seems that the reduction obtained at about 6 months is maintained over time, although only few studies followed the study population for long periods of follow-up. The reduction of the effect after

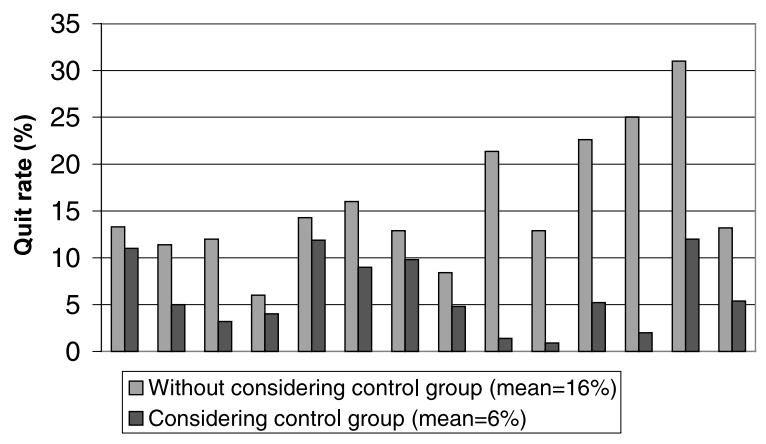

Figure 2. Intervention effect in smoking cessation programs at the worksite. Only trials reporting quit rates for the intervention group are included. For trials reporting more than one follow-up, we included the first data reported above 3 months of follow-up. For trials offering different kinds of intervention, we included the mean of the intervention effects. Studies are in the order of increasing length of follow-up.

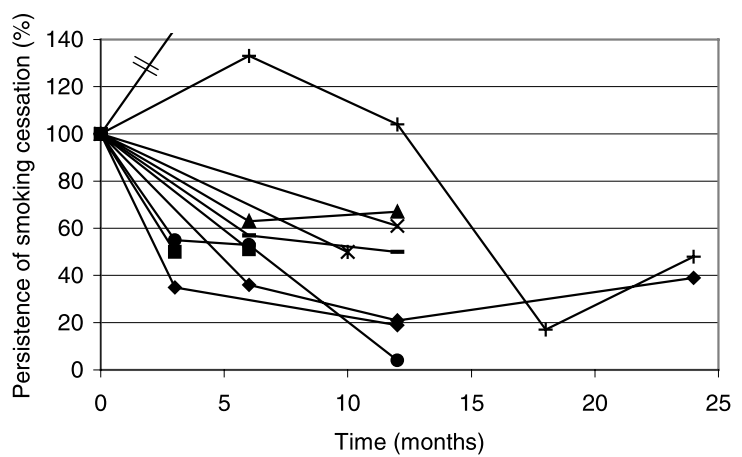

Figure 3. Persistence of smoking cessation after the end of the intervention. In most studies the persistence of the effect was measured as changes in quit rates. Some studies reported changes in the prevalence of smoking and continuous abstinence. In one study, indicated with a broken line, the quit rates increased 1 year after the end of the intervention. 
the end of the intervention may, in part, be due to a late effect of self-help material in the control groups. Razavi et al (21) evaluated the effectiveness of two relapse prevention programs and found that relapse was higher in the control group $(50.4 \%)$ versus the two intervention groups ( $42.2 \%$ and $46.6 \%)$ although the differences were not significant.

Efficiency increased with the length of the intervention up to 6 months (figure 4). A few studies offered intervention for more than 6 months $(10,17,26-28)$, and they did not indicate any additional beneficial effects when the intervention was prolonged. The intensity of the intervention, measured by the number of contacts, was weakly associated with higher smoking quit rates (figure 4). Although the highest quit rates were obtained in intense intervention programs $(22,29)$, high intensity did not always lead to a more successful intervention $(13,28,33)$. The quality parameters of these studies, such as participation rates, size of study, or
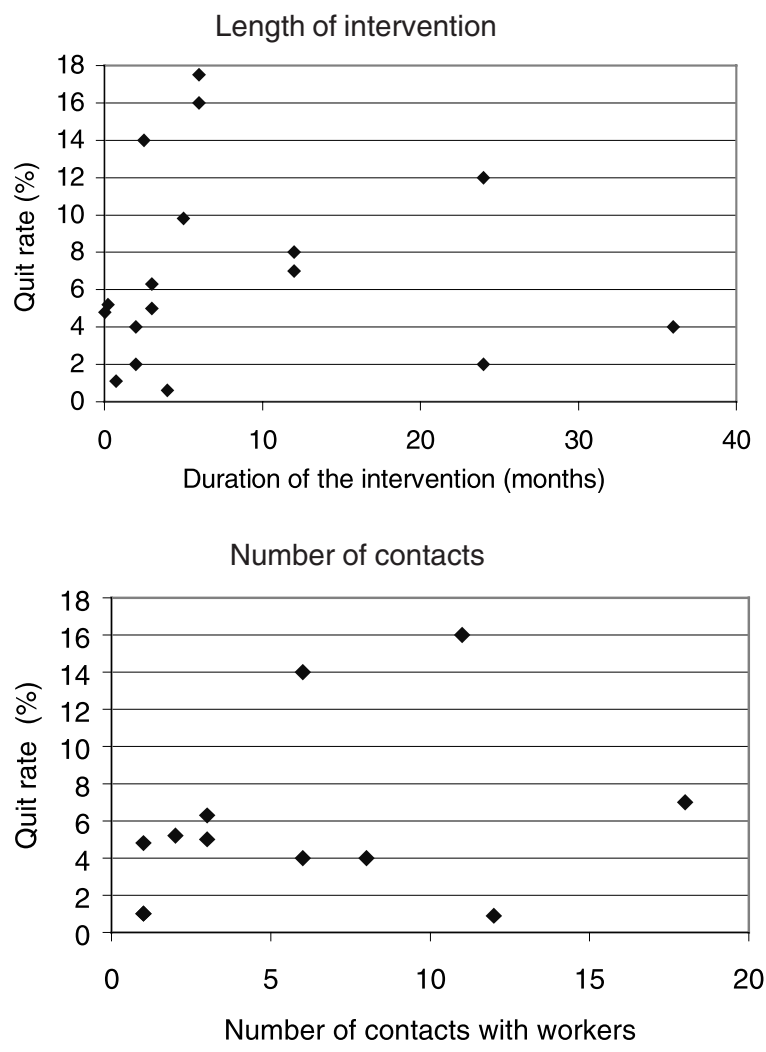

Figure 4. Effect of the length of the intervention and the number of contacts on quit rates. Only smoking cessation trials reporting quit rates for intervention groups were included. For the trials reporting more than one follow-up, we included the first data reported above 3 months of follow-up. For those offering different types of intervention, we included the mean of the intervention effects, unless the length of the intervention or the number of contacts differed between the groups. matching, did not account for the differences in the quit rates between the high-intensity intervention programs.

Trials including incentives or competitions reported higher quit rates $(8 \%)$ than those not offering incentives $(5 \%)$. Most of the former type of trials did not offer any kind of intervention to the control group, while most studies without incentives included a minimal intervention in the control group. Only five studies compared the effectiveness of providing incentives within the same trial $(13,15,18,20,29)$. Four found a higher smoking quit rate in the incentive group $(10.4 \%$ versus $7.5 \%$, $20 \%$ versus $16.5 \%$, and $12.9 \%$ versus $12 \%)(13,18,29)$ or a higher abstinence smoking rate (40\% versus $23 \%$ ) (20). In one of these studies the effect of the incentives was substantially reduced in the long-term (20), while in another (29) the long-term quit rates showed a negative effect of incentives. In one trial (13) effects were statistically significant only in the subgroup of less-educated workers (quit rates of $18.6 \%$ versus $8.8 \%$ ).

One trial examined the effect of social support among workers on the effectiveness of the health promotion programs. Actions in favor of nonsmoking, such as being asked by a fellow worker not to smoke, was correlated with greater changes in quit rates (standardized regression coefficient $0.195, \mathrm{P}<0.005)(12)$.

The effect of environmental changes, such as establishing nonsmoking areas, was assessed in two trials (16-28). When environmental changes were added to health education and follow-up support, an additional effect was found in one study (1.5\% reduction in smoking prevalence) (28), but not in the other (16).

Intervention trials on the reduction of cardiovascular disease risk, although frequently focusing on tobacco control, have not always measured outcomes related to smoking behavior. Significant reductions in mortality and morbidity have been reported $(30,33)$, but the extent to which these changes were due to smoking behavior modification was difficult to evaluate since these programs also included intervention focusing on diet, physical activity, and alcohol.

The effectiveness of tobacco control programs has been associated with some baseline characteristics of the study populations. It has been found to be higher among managers, moderate smokers $(<1$ daily packet of cigarettes or $<10$ cigarettes/day depending on the trial), smokers of light tobacco, smokers having had previous attempts at quitting smoking, smokers that found quitting significantly less difficult, and smokers who had smoked for less time $(8,11)$. Including incentives was effective for workers with less education (13).

Four trials used biochemical analyses to evaluate tobacco control $(14,20,22,29)$ and six validated selfreported changes in tobacco control measuring exhaled carbon monoxide $(8-10,13,17,19)$. Validation was assessed for small samples, and no consistent differences 
were found between the intervention and control groups. False positive results ranged from $7 \%$ to $41 \%(9,10$, $13,17)$. One study reported a kappa coefficient of 0.58 at inclusion and 0.38 at follow-up between reported changes and exhaled carbon monoxide (8).

\section{Nutrition}

Worksite health promotion trials on diet have focused on behavioral changes, particularly an increase or reduction in the consumption of specific food groups. Fruits, vegetables, and foods with a high proportion of fiber or fat have been the most common targets. Physiological outcomes, including cholesterol levels, body fat, and blood pressure have also been reported. Only body fat is included in this review (see the section on weight control) because the other factors are not directly related to cancer.

All 14 trials observed changes in the treatment group in the expected direction, for at least some of the outcomes measured, and for 11 the differences were statistically significant (figure 5). Statistically significant increases in vegetable intake were observed in the intervention group in six $(23,35-37,39,40)$ of seven trials (34). The increase in vegetable servings per day were reported in three trials and ranged from 0.09 to $0.19(35,36,39)$ (figure 5). Five of these studies also evaluated fruit intake $(23,35-37,39)$. Four of them $(23$, $35,37,39)$ obtained statistically significant increases, ranging from 0.11 to 0.24 servings per day $(35,36,39)$. In the three studies reporting both fruit and vegetable use, increases ranged from 0.18 to 0.5 servings per day $(23,35,37)$. Changes in fat intake reduction were statistically significant in $6(23,27,31,35,36,40)$ of the 10 available studies $(23,26,27,31,34-36,40-42)$. The magnitude of the change ranged from a decrease of $3.0 \%$ to an increase of $1.3 \%$ in the kilocalories from fat (23, $26,35,36,38,40,42)$. An increase in fiber intake, was observed in three $(35,40,42)$ of the five available trials $(23,36)$, ranging from 0.02 to 1.7 grams of fiber intake/ 1000 kilocalories.

Programs targeting environmental changes, such as modification of the food offered in the company canteen and vending machines were evaluated in five trials $(23,26,34,36,37)$. They all included some other kind of intervention. The results were similar to those obtained in trials not including environmental changes. Some of the intervention programs (7 of 13) included workers in the planning and implementing of the health promotion, but a larger effect could not be associated with this procedure $(23,26,27,31,34,39,42)$.

Five studies included more than one period of follow-up $(31,35,39-41)$. The percentage of change maintained at 6 or 12 months with respect to the intake increase or reduction ranged from $30 \%$ to $65 \%(35,39$,
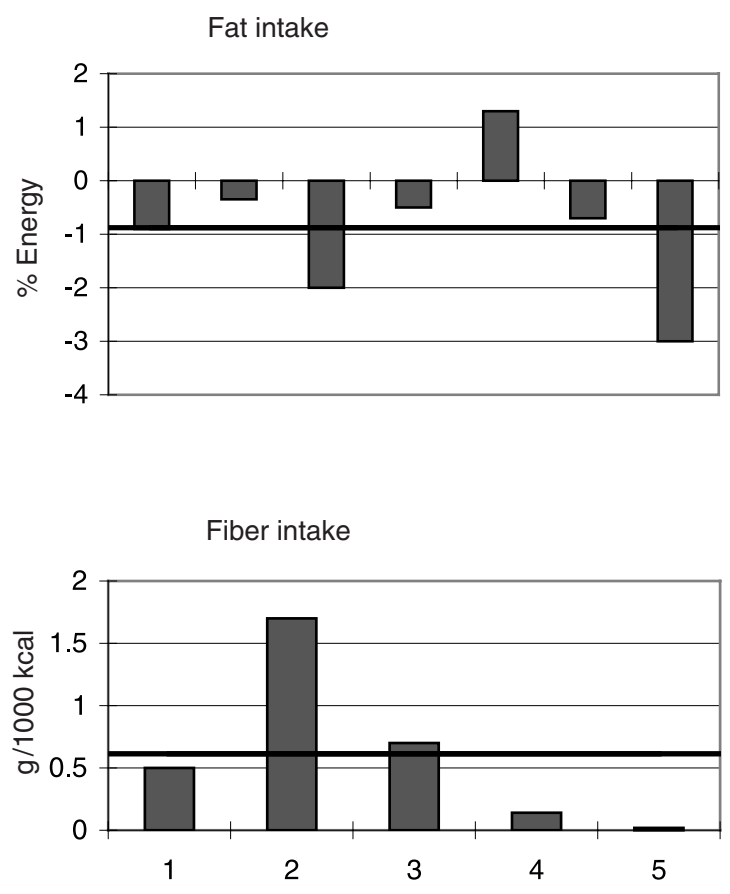

Fruit and vegetable intake

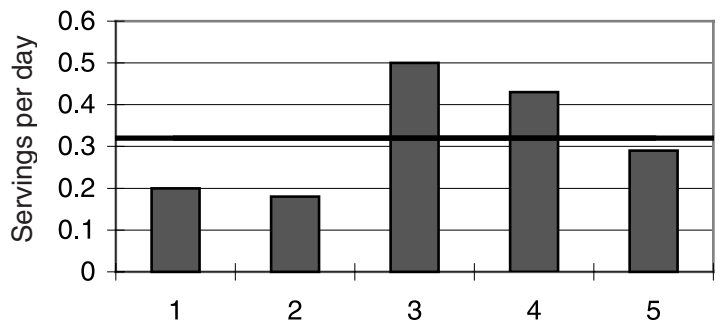

Figure 5. Intervention effect in health promotion programs at worksites on diet. Individual values for available trials are shown as bars and the mean of all the trials as a boldface line.

40). One study did not find any differences between the follow-up at 3 and 6 months (41).

\section{Physical activity}

Two types of physical activity intervention could be distinguished, that based on counseling and educational sessions and that offering facilities, space, or time to workers. The outcomes measured in the worksite health promotion programs on physical activity varied, including body fat, aerobic capacity, and the proportion of workers engaged in regular exercise (table 3 ).

The results of programs focusing exclusively on physical activity (44-46) were more consistent than those enhancing physical activity as part of a program with wider objectives $(24,25,29-34,43,47,48)$. Significant results were found in 7 of 13 studies $(25,34$, $43,45-48)$. Out of nine trials using educational sessions 
Table 3. Intervention effects of some of the health promotion programs at worksites using physical activity as a form of intervention.

\begin{tabular}{|c|c|c|}
\hline Reference & Outcome & $\begin{array}{l}\text { Changes in physical activity outcomes } \\
\text { (intervention minus control) }\end{array}$ \\
\hline Emmons et al (47), United States, 1999 & Proportion of workers engaged in regular exercise & $10.1 \%^{*}$ \\
\hline Peterson \& Aldana (46), United States, 1999, & $\begin{array}{l}\text { Physical activity level in kilocalories per kilogram of } \\
\text { body weight per week (percentage) }\end{array}$ & $\begin{array}{l}8.06(21 \%)^{\star} \text { (tailored intervention) } \\
3.78(9 \%)^{\star} \text { (generic intervention) }\end{array}$ \\
\hline Breslow et al (25), United States, 1990 & Energy spent in intense physical activity & $71 \%$ * \\
\hline $\begin{array}{l}\text { Gomel et al (29), Australia, } 1993 \text { \& Shephard } \\
\text { (45), Canada, } 1992\end{array}$ & $\begin{array}{l}\text { Aerobic capacity in maximal aerobic capacity } \\
{[\mathrm{ml} /(\mathrm{kg} \cdot \mathrm{min})]}\end{array}$ & $1-2$ \\
\hline $\begin{array}{l}\text { Bauer et al (31), United Kingdom, } 1985 \text { \& } \\
\text { Shannon et al (43), United States, } 1987\end{array}$ & $\begin{array}{l}\text { Leisure-time exercise (leisure-time physical activity, } \\
\text { scale score, range 5-15) }\end{array}$ & $1^{\mathrm{a}}$ \\
\hline Edye et al (32), Australia, 1989 & $\begin{array}{l}\text { Lack of fitness: pulse rate greater than } 120 \text { beats/min } \\
\text { after } 2 \text { minutes of stepping }\end{array}$ & $4 \%$ \\
\hline Heirich et al (44), United States, 1993 & $\begin{array}{l}\text { Scores ranging from } 1 \text { (never exercise) to } 5 \\
\text { ( } \geq 3 \text { a week) for different intervention groups }\end{array}$ & $-0.5-0.01$ \\
\hline Shephard (45), Canada, 1992 & Body fat & $-1.6 \% *$ \\
\hline Shephard (45), Canada, 1992 & Flexibility (cm) & $2^{*}$ \\
\hline Marcus et al (48), United States, 1998 & $\begin{array}{l}\text { Progress through stages of change } \\
\text { (\% progressed to action stage) }\end{array}$ & $17.5 \%{ }^{*}$ \\
\hline Kronenfeld et al (34), United States, 1987 & Perception as more active & $16 \%$ * \\
\hline Maes et al (24), The Netherlands, 1998 & Total life-style score (range 0-6) & 0.33 \\
\hline Spilman et al (33), United States, 1986 & Weekly physical exercise & No significant differences \\
\hline Kornitzer et al (30), Belgium, 1983 & Total mortality (cumulative difference) & $-17.5 \%{ }^{*}$ \\
\hline Kornitzer et al (30), Belgium, 1983 & $\begin{array}{l}\text { Nonfatal myocardial infarction (cumulative } \\
\text { difference) }\end{array}$ & $-26 \%$ * \\
\hline
\end{tabular}

a Statistically significant change in score only in one study (43).

${ }^{*} \mathrm{P}<0.05$.

and informative materials $(25,29,31-34,44,46,48)$ and evaluating outcomes directly related to physical activity, four reported significant changes $(25,34,46,48)$. Significant changes were reported in three $(44,46,48)$ of four trials (44) offering facilities, time, and space. One trial comparing both types of intervention found better results with educational activities focusing on behavioral changes, with $65 \%$ of at-risk employees exercising weekly, compared with 50\% when facilities were offered (44). One study examined the effectiveness of self-help intervention tailored to the individual's stage of motivational readiness for exercise adoption (48). Motivationally tailored intervention appeared to be more effective in nearly all the stages of readiness, with differences from $4 \%$ to $17 \%$ in the proportion of workers progressing to a higher stage, for example, from contemplation of starting exercise to actually starting it (48).

Some studies included at least two follow-up periods to evaluate the maintenance of the intervention effect over time $(29,30,45)$. The longest follow-up period was 7 years, and no reduction in the intervention effect was found. Participation in the activities was $13 \%$ at 7 years, the same as at the end of the intervention (45). Studies with repeated follow-up periods initially showed a change in the direction expected, but later a reduction occurred in this change $(29,30)$. Among all the remaining studies that reported data only from one follow-up, four evaluated long-term effects at 2, 3, or 10 years $(25,31,32,44)$. The study evaluating a 10 year period did not find any difference between the control and intervention groups (31).

\section{Weight control}

Weight control programs were offered in three studies $(22,43,49)$. Other studies aiming, for example, to reduce cardiovascular risks, offered intervention in nutrition or physical activity and also reported body fat changes $(28,29,32,38,45)$. The results varied among the studies, the changes in body weight ranging from a 0.25-kilogram increase to a 3.5-kilogram decrease (22, $28,32,43,49)$. The changes achieved in programs including weight control evaluation after a short-term period $(43,49)$ were greater than those of studies reporting longer term data, at 2 to 3 years $(22,32)$. Body fat reduction ranged from $0.45 \%$ to $1.19 \%(29,45)$, and the body mass index reduction ranged from 0.3 (29) to -0.3 (38). Maintenance of the intervention effect over 
1 year was assessed in one study with almost no reduction in the effect being found (29).

\section{Other risk factors}

Three alcohol intervention programs were identified. Kishchuk (50) reported significant improvement in alcohol knowledge, socially responsible attitudes, and feelings of self-efficacy and a statistically significant reduction in weekly consumption in the treatment group compared with the control group (decrease of 1.5 drinks/ week). In the study by Richmond et al (51) a decrease of 4.8 and 0.4 drinks/week was found for the men and women, respectively, but the results were statistically significant only for the women. A reduction in regular excessive drinking and binge drinking was seen among the men, but it was not significant. The third study (34) included alcohol among other types of life-style behavior and found a statistically significant higher increase for moderate drinkers (among all drinkers) in the intervention group (from $34 \%$ to $50 \%$ ) than in the control group (from $38 \%$ to $44 \%$ ).

Reducing occupational exposure to solar radiation was the objective of one program (52). The intervention, based on awareness and change of behavior, led to a significant improvement in solar protection knowledge and behavior among the participating workers, such as a $16 \%$ increase in the number of workers using sunscreen.

In neither the alcohol nor the solar radiation programs was there a follow-up of the effects obtained at posttests.

\section{Discussion}

The overall evidence from the 45 controlled trials evaluating worksite health promotion for cancer risk factors indicates a modest but positive effect. For smoking cessation, this effect was slightly larger than that reported in several large community-based trials. The bulk of the evidence comes from smoking cessation trials, but the effect was found for interventions focusing on all other risk factors also. Previous reviews on health promotion trials at work have also supported a positive effect (36, 63-65). A few of these reviews, for example, that of Glanz et al (5), applied quality criteria to classify the trials evaluated but did not seem to have based their conclusions on trials considered to be of higher quality with respect to their design. Furthermore none of the existing reviews provided a comprehensive quantitative analysis. When only the big and properly controlled trials included in this review are considered, the results of the health promotion trials at work appear to be less impressive than those frequently quoted.
A quantitative approach to intervention effects and intervention component effectiveness necessarily implies simplifications. There are many differences between the trials, for example, target population, design, or intervention strategy, which may affect the results obtained. Control for these factors or a comparison of different options presents difficulties due to the insufficient information provided by many trials on the intervention delivered.

\section{Design of the trials}

We reviewed only the trials that included a control group. The use of a control group is necessary to discriminate intervention effects from population trends and to take into account changes in the way a person behaves because of the mere awareness of being under observation (66). The interpretation of the results of the trials depends greatly on whether the control group was taken into account in the analysis or not. Without this comparison, estimates on smoking cessation would have been two to three times higher than those found when comparing with a control group. This phenomenon explains the wide discrepancy in the estimates of this review from the higher ones provided in reviews without a strict selection of trials (3). The use of control groups receiving some kind of intervention either intentionally or unintentionally, may, however, also bias the results negatively. Negative bias may occur through contamiation of the information among workers and transfer of the intervention effects from those participating to those not participating in the health promotion activities (12). Contamination of the intervention stresses the need for cluster assignment rather than individual assignment.

Participation rates for health promotion activities have been seldom reported for the original target population. Low participation rates in interventions (ie, presence in the health promotion activities) have probably helped to decrease the effectiveness of these programs (64). The response rates at both the baseline assessment and follow-up were around 50\%. Self-selection bias is a generalized feature when participation rates and recruitment intensity are low. This bias would tend to inflate results unless close attention is given to appropriate evaluation methods and design procedures (67).

\section{Intervention effects}

Results from the tobacco control programs indicated a quit rate of about $6 \%$ that could be attributed to the workplace intervention. A similar, although somewhat lower quit rate of $1.8 \%$ was found in analyses of controlled community smoking cessation trials (68).

Trials focusing on diet also identified positive but modest intervention effects. A meta-analysis of 
community-based health promotion programs on diet (69) found similar fat intake changes when the number of contacts received by the participants was lower than 10. In community trials with more than 10 contacts, the reduction in fat intake was five times that observed in health promotion trials at work. Among trials at worksites, only 3 of 13 contacted the workers repeatedly, and only 1 referred to fat intake.

All the existing trials promoting physical activity reported positive effects, even though statistically significant results were obtained in only about half of the trials. Statistically significant results were mostly obtained in programs including fitness facilities or classes as compared with programs without these advantages.

The two available programs focusing on alcohol found some intervention effects, as reported in a previous review (63). It is not evident, however, whether the reduction in alcohol intake occurred among the at-risk (high consumption) population or among those who already had low and safe consumption.

A trial on solar radiation focused on primary and secondary preventive measures and reported encouraging effects on the increase in protective measures such as the use of sunscreens by workers. A similar program offered at the community level found lower cumulative mortality rates for melanoma in the intervention region than in neighboring regions (70). Existing trials were directed towards occupational exposures. We could not identify any prevention trials dealing with leisure-time sun exposure.

\section{Persistence of the intervention effects}

Behavioral changes are difficult to maintain over time, and relapse rates of $40 \%$ to $80 \%$ were observed in the tobacco control trials. Similar relapse rates (50-90\%) are commonly found in community trials for smoking and other disorders or risk factors such as alcoholism, obesity, and drug addiction (67). Relapse seemed to occur mostly in the first 6 months after the intervention, a result that has frequently been reported in other trials (71). These results probably indicate that a 6-month followup period would be sufficient in health promotion trials to identify almost all the relapse occurrences. There is little evidence, however, suggesting that there is any specific point beyond which relapse should not be considered (67), since the reviewed health promotion programs at work rarely reported long-term effectiveness after the end of the intervention. Neither in alcohol programs nor in solar radiation programs has there been any follow-up of the effects obtained at posttests.

The decrease in the effects observed over time is not always due to relapses in the intervention group. Occasionally it may be due to a late effect in the control group, particularly among those receiving self-help materials. This minimal intervention effect may take place with a longer latency time than that of the intervention group (9).

\section{Factors that affect effectiveness}

Various policies have been proposed to improve the effectiveness of trials by increasing participation rates and facilitating and encouraging participants to adopt healthier life-styles and maintain them over time. Many of these policies use a theoretical basis including concepts of cognitive theory, social support principles, and models of behavioral change $(72,73,74)$. Factors thought to improve effectiveness include incentives, acting as a direct positive reinforcement by rewarding people who change to a healthier option; environmental changes, creating opportunities for action and removing barriers at the worksite level; tailored intervention, offering different messages according to the individual characteristics obtained in baseline surveys, generally following the stage-of-change model; involvement of workers in planning and implementing the intervention, suiting better workers' health priorities and identifying themselves with the program; intensity of the intervention, regarding the length or number of contacts with workers; and, finally, involvement of family or co-workers, acting as support to adopt and maintain the healthy options. However, the influence of many of these features has not been clearly associated with larger intervention effects.

In tobacco control programs a weak positive relation was found with a longer duration of the intervention and with the number of contacts. Health promotion trials focusing on factors other than smoking have too few and too heterogeneous data on intensity and duration of the worksite for these associations to be evaluated. In community-based trials on diet, a larger effect was observed in the trials with a higher number of contacts (69).

Comparisons between worksite trials on tobacco control regarding other components, such as incentives, company participation in intervention planning or implementation, environmental changes, focus on maintenance, or tailored message, were not feasible since they may be influenced by other design or intervention differences apart from the specific features examined. Within-trial comparisons to evaluate specific features have been done less often, but they found that the use of financial incentives, continuous support, and tailored messages were associated with improvement in the intervention effect. The impact, however, of incentives on quit rates was not only not maintained in the long-term but, in one study, seemed to be counterproductive.

Worksite trials on diet involving environmental intervention, such as changes in the worksite canteen or vending machines, did not prove to be more efficient 
than those without environmental components. A similar conclusion was reached in a previous review of worksite multicomponent health promotion programs (4).

Few trials evaluated the effect of providing tailored, as opposed to generic, strategies. The results indicated consistently larger intervention effects when a tailored approach was used. A similar conclusion has been reached in another review on worksite health promotion (4) and in community-based trials regarding physical activity and tobacco control $(68,75)$.

It has been stated that, to optimize resources and results, it is necessary to integrate different risk factors into health promotion programs $(36,52)$. Intuitively this assumtion seems apparent since life-style risk factors are often related and focusing on one specific factor may help modify another. There is only little direct evidence on this possibility (76). Existing studies do not evaluate the relative effectiveness of programs focusing on single or, alternatively, multiple risk factors.

\section{Recommendations for future health promotion trials at worksites}

Trials in North America have consistently shown a modest but positive effect of health promotion trials at worksites. Although much of the research has concentrated on tobacco control, findings for other cancer risk factors have indicated similar patterns. Low participation seems to be one of the main weak points of worksite health promotion. The involvement of workers in the preparation and conduct of the trials appears to be the only clue provided by existing studies on how participation could be increased. Ways of increasing participation and effectiveness are among the main issues to be resolved in future research. For participation to be evaluated, it is essential that studies report participation rates for different study phases. Increased duration, multiple contacts, tailored interventions, incentives, and continuous support are among the factors that seem to affect effectiveness, but data are not entirely consistent. These and other factors will have to be evaluated further. In addition, the information provided on the intervention delivered should be more complete.

There exists less experience on health promotion at work in Europe. Trials in North America may not be directly applicable to those in other industrialized countries with different sociocultural characteristics. Studies to evaluate the effectiveness of worksite health promotion should be conducted in those countries.

Existing studies indicate that a minimum of 6 months is necessary to evaluate the maintenance of interventions. There exist, however, too few studies examining effects over a longer term. Existing large studies could provide this evidence.
Finally, most of the worksite health promotion programs were conducted in large or medium-sized workplaces. The effectiveness of health promotion programs should be assessed in other kinds of worksites, including smaller worksites, those of workers in the primary sector, and those employing minorities. Although major intervention programs would not be feasible at small worksites, evidence from existing trials indicates that relatively modest interventions may have an effect.

\section{Concluding remarks}

Substantial evidence from health promotion programs at worksites, mostly from North America, currently shows that these trials have a modest but positive effect. For smoking cessation, this effect seems larger than that obtained in community intervention trials. Most trials have focused on tobacco control, but trials on diet (increase in fruit and vegetable consumption, decrease in fat consumption), alcohol, physical activity, overweight, and solar radiation have all shown the same positive trends. The reviewed health promotion programs at work included different intervention components and presented wide differences in issues such as recruitment intensity and worksite and workforce baseline characteristics. Low participation rates appear to be one of the main problems of worksite health promotion, and there is little empirical evidence regarding factors related to higher participation and lower attrition rates. Specific features that increase the effectiveness of the trials seem to be at least a 6-month duration of the intervention, repeated contacts with the participants, continuous support, and tailored messages. There is less evidence for the long-term effectiveness of incentives. Many of the other recommendations that have been made to increase effectiveness, although intuitively appealing, are not based on empirical data.

\section{References}

1. - Community intervention trial for smoking cessation (COMMIT): I. cohort results from a four-year community intervention. Am J Public Health 1995;85(2):183-92.

2. - Community intervention trial for smoking cessation (COMMIT): II. Changes in adult cigarette smoking prevalence. Am J Public Health 1995;85(2):193-200.

3. Fisher KJ, Glasgow RE, Terborg JR. Work site smoking cessation: a meta-analysis of long-term quit rates from controlled studies. J Occup Med 1990;32(5):429-39.

4. Heaney CA, Goetzel RZ. A review of health-related outcomes of multi-component worksite health promotion programs. Am J Health Promot 1997;11(4):290-307.

5. Glanz K, Sorensen G, Farmer A. The health impact of worksite nutrition and cholesterol intervention programs. Am J Health Promot 1996;10(6):453-70.

Scand J Work Environ Health 2002, vol 28, no 3 
6. Wilson MG, Holman PB, Hammock A. A comprehensive review of the effects of worksite health promotion on healthrelated outcomes. Am J Health Promot 1996;10(6):429-35.

7. Glanz K, Mullis RM. Environmental interventions to promote healthy eating: a review of models, programs, and evidence. Health Educ Q 1988;15(4):395-415.

8. Lang T, Nicaud V, Slama K, Hirsch A, Imbernon E, Goldberg M, et al. Smoking cessation at the workplace: results of a randomised controlled intervention study. J Epidemiol Community Health 2000;54(5):349-54.

9. Omenn GS, Thompson B, Sexton M, Hessol N, Breitenstein B, Curry S, et al. A randomized comparison of worksitesponsored smoking cessation programs. Am J Prev Med 1988;4(5):261-7.

10. Jason LA, Lesowitz T, Michaels M, Blitz C, Victors L, Dean $\mathrm{L}$, et al. A worksite smoking cessation intervention involving the media and incentives. Am J Community Psychol 1989; 17(6):785-99.

11. Jason LA, Gruder CL, Martino S, Flay BR, Warnecke R, Thomas N. Work site group meetings and the effectiveness of a televised smoking cessation intervention. Am J Community Psychol 1987;15(1):57-72.

12. Sorensen G, Lando H, Pechacek TF. Promoting smoking cessation at the workplace: results of a randomized controlled intervention study. J Occup Med 1993;35(2):121-6.

13. Glasgow RE, Hollis JF, Ary DV, Boles SM. Results of a year-long incentives-based worksite smoking-cessation program. Addict Behav 1993;18(4):455-64.

14. Li VC, Kim YJ, Ewart CK, Terry PB, Cuthie JC, Wood J, et al. Effects of physician counseling on the smoking behavior of asbestos-exposed workers. Prev Med 1984;13(5):462-76.

15. Windsor RA, Lowe JB, Bartlett EE. The effectiveness of a worksite self-help smoking cessation program: a randomized trial. J Behav Med 1988;11(4):407-21.

16. Hymowitz N, Campbell K, Feuerman M. Long-term smoking intervention at the worksite: effects of quit-smoking groups and an "enriched milieu" on smoking cessation in adult white-collar employees. Health Psychol 1991; 10(5):366-9.

17. Willemsen MC, de Vries H, van Breukelen G, Genders R. Long-term effectiveness of two Dutch work site smoking cessation programs. Health Educ Behav 1998;25(4):418-35.

18. Jason LA, Salina D, McMahon SD, Hedeker D, Stockton M. A worksite smoking intervention: a 2 year assessment of groups, incentives and self-help. Health Educ Res 1997;12(1):129-38.

19. Kadowaki T, Watanabe M, Okayama A, Hishida K, Ueshima $\mathrm{H}$. Effectiveness of smoking-cessation intervention in all of the smokers at a worksite in Japan. Ind Health 2000;38(4):396-403.

20. Koffman DM, Lee JW, Hopp JW, Emont SL. The impact of including incentives and competition in a workplace smoking cessation program on quit rates. Am J Health Promot 1998;13(2):105-11.

21. Razavi D, Vandecasteele H, Primo C, Bodo M, Debrier F, Verbist $\mathrm{H}$, et al. Maintaining abstinence from cigarette smoking: effectiveness of group counselling and factors predicting outcome. Eur J Cancer 1999;35(8):1238-47.

22. Jeffery RW, Forster JL, French SA, Kelder SH, Lando HA, McGovern PG, et al. The healthy worker project: a work-site intervention for weight control and smoking cessation. Am J Public Health 1993;83(3):395-401.

23. Sorensen G, Thompson B, Glanz K, Feng Z, Kinne S, DiClemente $\mathrm{C}$, et al. Work site-based cancer prevention: primary results from the Working Well Trial. Am J Public Health 1996;86(7):939-47.

24. Maes S, Verhoeven C, Kittel F, Scholten H. Effects of a Dutch work-site wellness-health program: the Brabantia project. Am J Public Health 1998;88(7):1037-41.

25. Breslow L, Fielding J, Herrman AA, Wilbur CS. Worksite health promotion: its evolution and the Johnson \& Johnson experience. Prev Med 1990;19:13-21.

26. Glasgow RE, Terborg JR, Hollis JF, Severson HH, Boles SM. Take heart: results from the initial phase of a work-site wellness program. Am J Public Health 1995;85(2):209-16.

27. Glasgow RE, Terborg JR, Strycker LA, Boles SM, Hollis JF. Take Heart II: replication of a worksite health promotion trial. J Behav Med 1997;20(2):143-61.

28. Erfurt JC, Foote A, Heirich MA. Worksite wellness programs: incremental comparison of screening and referral alone, health education, follow-up counseling, and plant organization. Am J Health Promot 1991;5(6):438-48.

29. Gomel M, Oldenburg B, Simpson JM, Owen N. Work-site cardiovascular risk reduction: a randomized trial of health risk assessment, education, counseling, and incentives. Am J Public Health 1993;83(9):1231-8.

30. Kornitzer M, De Backer G, Dramaix M, Kittel F, Thilly C, Graffar M, et al. Belgian heart disease prevention project: incidence and mortality results. Lancet 1983;1(8333):10661070.

31. Bauer RL, Heller RF, Challah S. United Kingdom heart disease prevention project: 12-year follow-up of risk factors. Am J Epidemiol 1985;121(4):563-9.

32. Edye BV, Mandryk JA, Frommer MS, Healey S, Ferguson DA. Evaluation of a worksite programme for the modification of cardiovascular risk factors. Med J Aust 1989;150(10): $574,576-8,581$.

33. Spilman MA, Goetz A, Schultz J, Bellingham R, Johnson D. Effects of a corporate health promotion program. J Occup Med 1986;28(4):285-9.

34. Kronenfeld JJ, Jackson K, Blair SN, Davis K, Gimarc JD, Salisbury Z, et al. Evaluating health promotion: a longitudinal quasi-experimental design. Health Educ Q 1987;14(2): 123-39.

35. Tilley BC, Glanz K, Kristal AR, Hirst K, Li S, Vernon SW, et al. Nutrition intervention for high-risk auto workers: results of the Next Step trial. Prev Med 1999;28(3):284-92.

36. Hebert JR, Stoddard AM, Harris DR, Sorensen G, Hunt MK, Morris DH, et al. Measuring the effect of a worksite-based nutrition intervention on food consumption. AEP 1993; 3(6):629-35.

37. Sorensen G, Stoddard A, Peterson K, Cohen N, Hunt MK, Stein $\mathrm{E}$, et al. Increasing fruit and vegetable consumption through worksites and families in the treatwell 5-a-day study. Am J Public Health 1999;89(1):54-60.

38. Braeckman L, De Bacquer D, Maes L, De Backer G. Effects of a low-intensity worksite-based nutrition intervention. Occup Med (Lond) 1999;49(8):549-55.

39. Buller DB, Morrill C, Taren D, Aickin M, Sennott-Miller L, Buller MK, et al. Randomized trial testing the effect of peer education at increasing fruit and vegetable intake. J Natl Cancer Inst 1999;91(17):1491-500.

40. Sasaki S, Ishikawa T, Yanagibori R, Amano K. Change and 1-year maintenance of nutrient and food group intakes at a 12-week worksite dietary intervention trial for men at high risk of coronary heart disease. J Nutr Sci Vitaminol 2000;46(1):15-22.

41. Reynolds KD, Gillum JL, Hyman DJ, Byers T, Moore SA, 
Paradis G, et al. Comparing two strategies to modify dietary behavior and serum cholesterol. J Cardiovasc Risk 1997;4(1):1-5.

42. Barratt A, Reznik R, Irwig L, Cuff A, Simpson JM, Oldenburg B, et al. Work-site cholesterol screening and dietary intervention: the Staff Healthy Heart project. Steering Committee. Am J Public Health 1994;84(5):779-82.

43. Shannon B, Hendricks M, Rollins P, Schwarts RM. A comprehensive evaluation of a worksite nutrition and weightcontrol program. J Nutr Educ 1987;19(3): 109-116

44. Heirich MA, Foote A, Erfurt JC, Konopka B. Work-site physical fitness programs. Comparing the impact of different program designs on cardiovascular risks. J Occup Med 1993;35(5):510-7.

45. Shephard RJ. Twelve years experience of a fitness program for the salaried employees of a Toronto life assurance company. Am J Health Promot 1992;6(4):292-301.

46. Peterson TR, Aldana G. Improving exercise behavior: an application of the stages of change model in a worksite setting. Am J Health Promot 1999;13(4):229-32.

47. Emmons KM, Linnan LA, Shadel WG, Marcus B, Abrams DB. The working healthy project: a worksite health-promotion trial targeting physical activity, diet, and smoking. J Occup Environ Med 1999;41(7):545-55.

48. Marcus BH, Emmons KM, Simkin-Silverman LR, Linnan LA, Taylor ER, Bock BC, et al. Evaluation of motivationally tailored vs. standard self-help physical activity interventions at the workplace. Am J Health Promot 1998;12(4):246-53.

49. Anderson JV, Mavis BE, Robison JI, Stoffelmayr BE. A work-site weight management program to reinforce behavior. J Occup Med 1993;35(8):800-4.

50. Kishchuk N, Peters C, Towers AM, Sylvestre M, Bourgault $\mathrm{C}$, Richard L. Formative and effectiveness evaluation of a worksite program promoting healthy alcohol consumption. Am J Health Promot 1994;8(5):353-62.

51. Richmond R, Kehoe L, Heather N, Wodak A. Evaluation of a workplace brief intervention for excessive alcohol consumption: the workscreen project. Prev Med 2000;30(1):5163.

52. Girgis A, Sanson-Fisher RW, Watson A. A workplace intervention for increasing outdoor workers' use of solar protection. Am J Public Health 1994;84(1):77-81.

53. Sorensen G, Morris DM, Hunt MK, Hebert JR, Harris DR, Stoddard A, et al. Work-site nutrition intervention and employees' dietary habits: the treatwell program. Am J Public Health 1992;82(6):877-80.

54. Hunt MK, Hebert JR, Sorensen G, Harris DR, Hsieh J, Morris $\mathrm{DH}$, et al. Impact of a worksite cancer prevention program on eating patterns of workers. J Nutr Educ 1993; 25(5):236-44.

55. Hebert JR, Harris DR, Sorensen G, Stoddard AM, Hunt MK, Morris DH. A work-site nutrition intervention: its effects on the consumption of cancer-related nutrients. Am J Public Health 1993;83(3):391-4.

56. Hunt MK, Lederman R, Stoddard A, Potter S, Phillips J, Sorensen G. Process tracking results from the Treatwell 5-aday worksite study. Am J Health Promot 2000;14(3):17987.

57. Leatt P, Hattin H, West C, Shephard RJ. Seven year followup of employee fitness program. Can J Public Health 1988;79(1):20-5.

58. Cox M, Shephard RJ, Corey P. Influence of an employee fitness programme upon fitness, productivity and absenteeism. Ergonomics 1981;24(10):795-806.

59. Sorensen G, Stoddard A, Hunt MK, Hebert JR, Ockene JK, Avrunin JS, et al. The effects of a health promotion-health protection intervention on behavior change: the well works study. Am J Public Health 1998;88(11):1685-90.

60. Blair SN, Piserchia PV, Wilbur CS, Crowder JH. A public health intervention model for work-site health promotion: impact on exercise and physical fitness in a health promotion plan after 24 months. JAMA 1986;255(7):921-6.

61. Rose G, Tunstall-Pedoe HD, Heller RF. UK heart disease prevention project: incidence and mortality results. Lancet 1983;1(8333):1062-6.

62. Donner A, Brown KS, Brasher P. A methodological review of non-therapeutic intervention trials employing cluster randomization, 1979-1989. Int J Epidemiol 1990;19(4):795-800.

63. Roman PM, Blum TC. Alcohol: a review of the impact of worksite interventions on health and behavioral outcomes. Am J Health Promot 1996;11(2):136-49.

64. Shephard RJ. Twelve years experience of a fitness program for the salaried employees of a Toronto life assurance company. Am J Health Promot 1992;6(4):292-301.

65 Pelletier KR. A review and analysis of the clinical and costeffectiveness studies of comprehensive healt promotion and disease management programs at the worksite: 1995-1998 update (IV). Am J Health Promot 1999;13(6):333-45.

66. Grufferman S. Complexity and the Hawthorne effect in community trials. Epidemiology 1999;10(3):209-10.

67. DeJoy DM, Wilson MG. Critical issues in worksite health promotion. Boston (MA): Allyn and Bacon, 1995.

68. Law M, Tang JL. An analysis of the effectiveness of interventions intended to help people stop smoking. Arch Intern Med 1995;155(18):1933-41.

69. Brunner E, White I, Thorogood M, Bristow A, Curle D, Marmot M. Can dietary interventions change diet and cardiovascular risk factors? A meta- analysis of randomized controlled trials. Am J Public Health 1997;87(9):1415-22.

70. Cristofolini M, Bianchi R, Boi S, DeCarli A, Micciolo R, Cristofolini $\mathrm{P}$, et al. Effectiveness of the health campaign for the early diagnosis of cutaneous melanoma in Trentino, Italy. J Dermatol Surg Oncol 1993;19(2):117-20.

71. Klesges RC, Vasey MM, Glasgow RE. A worksite smoking modification competition: potential for public health impact. Am J Public Health 1986;76(2):198-200.

72. Bandura A. Social foundations of thought and action: a social cognitive theory. Englewood Cliffs (NJ): Prentice Hall, 1986.

73. Heaney C, Israel B. Social networks and social support. Health behavior and health education, 2nd ed. San Francisco (CA): Jossey-Bass, 1997:179-205.

74 Prochaska JO, DiClemente CC, Norcross JC. In search of how people change: applications to addictive behaviors. Am Psychol 1992;47:1102-14.

75. Rosenfeld O, Tenenbaum G, Ruskin H, Halfon ST. Behavioural modifications following a physical activity programme in the israeli pharmaceutical industry. Aust J Sci Med Sport 2000;22(4):93-6.

76. Marcus BH, Owen N, Forsyth LH, Cavill NA, Fridinger F. Physical activity interventions using mass media, print media, and information technology. Am J Prev Med 1998;15(4):362-78.

Received for publication: 17 September 2001 